Meta

Journal des traducteurs

Translators' Journal

\title{
La traducción al servicio de una línea editorial: la primavera árabe en el diario El País
}

\section{María José Hernández Guerrero}

Volume 57, numéro 4, décembre 2012

Journalisme et traduction

Journalism and Translation

URI : https://id.erudit.org/iderudit/1021227ar

DOI : https://doi.org/10.7202/1021227ar

Aller au sommaire du numéro

Éditeur(s)

Les Presses de l’Université de Montréal

ISSN

0026-0452 (imprimé)

1492-1421 (numérique)

Découvrir la revue

Citer cet article

Hernández Guerrero, M. J. (2012). La traducción al servicio de una línea editorial: la primavera árabe en el diario El País. Meta, 57(4), 960-976. https://doi.org/10.7202/1021227ar
Résumé de l'article

Les rubriques d'opinion de la presse sont devenues de vraies tribunes, un lieu approprié pour le débat d'idées où se réunissent toute une série d'intellectuels qui débattent leurs opinions sur tout type de sujets d'actualité. Dans la presse espagnole, ces articles ne sont pas seulement signés par des figures nationales : une grande partie est rédigée par des personnalités étrangères dont les textes doivent être traduits pour leur nouveau public. L’objectif du présent travail est de découvrir de quelle manière la traduction fonctionne dans les rubriques d'opinion de la presse espagnole, comment elle est utilisée et dans quel but. Nous avons donc centré notre analyse sur la position adoptée par le quotidien espagnol El País, dans le cas d'un événement de grande retombée médiatique : le printemps arabe qui a commencé en janvier 2011. À l'aide d'une méthode descriptive, nous avons étudié le poids de la traduction dans le cadre des activités d'une entreprise journalistique afin d'établir ses axes d'action, de déterminer ses lignes de conduite et sa portée dans la culture cible.
Ce document est protégé par la loi sur le droit d'auteur. L'utilisation des services d'Érudit (y compris la reproduction) est assujettie à sa politique d'utilisation que vous pouvez consulter en ligne.

https://apropos.erudit.org/fr/usagers/politique-dutilisation/ 


\title{
La traducción al servicio de una línea editorial: la primavera árabe en el diario El País
}

\author{
MARÍA JOSÉ HERNÁNDEZ GUERRERO \\ Universidad de Málaga, Málaga, España \\ mjhernandez@uma.es
}

\begin{abstract}
RÉSUMÉ
Les rubriques d'opinion de la presse sont devenues de vraies tribunes, un lieu approprié pour le débat d'idées où se réunissent toute une série d'intellectuels qui débattent leurs opinions sur tout type de sujets d'actualité. Dans la presse espagnole, ces articles ne sont pas seulement signés par des figures nationales: une grande partie est rédigée par des personnalités étrangères dont les textes doivent être traduits pour leur nouveau public. L'objectif du présent travail est de découvrir de quelle manière la traduction fonctionne dans les rubriques d'opinion de la presse espagnole, comment elle est utilisée et dans quel but. Nous avons donc centré notre analyse sur la position adoptée par le quotidien espagnol El País, dans le cas d'un événement de grande retombée médiatique: le printemps arabe qui a commencé en janvier 2011. À l'aide d'une méthode descriptive, nous avons étudié le poids de la traduction dans le cadre des activités d'une entreprise journalistique afin d'établir ses axes d'action, de déterminer ses lignes de conduite et sa portée dans la culture cible.
\end{abstract}

\begin{abstract}
The opinion sections in newspapers have become ideal platforms for debating ideas where many intellectuals offer opinions on a wide range of subjects. These platforms are open both to Spanish intellectuals and to a growing number of influential international figures whose opinions are reaching a new readership through their translation in the Spanish press. The present article aims to study how translation operates in the opinion sections in the Spanish press, how it is used and with what aims. For this purpose, we have focused on a newspaper with a wide readership, the Spanish daily El País, and its position with respect to an event with global repercussions, namely, the so-called Arab Spring, i.e. the Arab Rebellions, which started in January 2011. By using a descriptive method, we analyse the use that a specific communication enterprise gives to translation with the aim of establishing its agenda, determining the guidelines it follows and its influence on the target culture.
\end{abstract}

\section{MOTS-CLÉS/ KEYWORDS}

traduction dans la presse, politique de traduction, textes journalistiques traduits, presse écrite espagnole, printemps arabe

press translation, translation policy, translated journalistic texts, Spanish written press, Arab Spring

\section{Introducción}

No resulta extraño que instituciones que a primera vista parecen irrelevantes en lo que a actividad traductora se refiere estén implicadas en la producción, comercialización y recepción de traducciones y hagan uso de la traducción para conseguir ciertas metas ideológicas. Los medios de comunicación representan uno de los casos 
más evidentes de este fenómeno: se sirven de la traducción para alcanzar ciertos objetivos, pero este hecho sigue pasando completamente inadvertido.

En el panorama mundial de los medios de comunicación, la prensa desempeña un papel básico e insustituible en la formación de la opinión pública. Ya sea en formato papel o en formato digital, llega a un considerable número de lectores, lo que le otorga una inmensa proyección social. Las secciones de opinión de los periódicos se han convertido en auténticas tribunas, en el lugar apropiado para el debate de ideas, y ahí acude toda una serie de intelectuales que exponen sus opiniones sobre los temas de actualidad más variados. En la prensa española, estas tribunas no solo están abiertas a los intelectuales nacionales, sino que una proporción importante de estos artículos de opinión tiene como autores a figuras internacionales, que escriben en inglés, francés y otras lenguas que llegan a la nueva audiencia a través de la traducción. La tribuna es un artículo de opinión que se caracteriza por recoger opiniones de personas ajenas a la redacción, de las que no se responsabiliza el medio informativo (López de Zuazo Algar 1990: 204; Martínez de Sousa 1992: 519¹). Las traducciones de estos artículos son frecuentes en la prensa de prestigio española, con un volumen nada desdeñable en algunos periódicos. Los últimos datos disponibles corresponden a 2008 y arrojan un porcentaje de traducción del 18,34\% en el diario El País, mientras que en su inmediato competidor, El Mundo, fue del 22,75\% (Hernández Guerrero 2009: 113-114).

Estas tribunas traducidas de procedencia internacional propagan discursos globales, que interactúan con los discursos locales y contribuyen a forjar corrientes ideológicas en la cultura receptora, entendidas estas como las representaciones sociales compartidas por determinados grupos. Estos discursos no constituyen una colección arbitraria de creencias sociales, sino esquemas específicos de grupos, que se organizan en torno a un número de categorías que representan la identidad, la estructura social y la posición del grupo (Van Dijk 2005: 287). De esta forma los discursos ideológicos se convierten en la base de actitudes sociales.

El objetivo de este artículo es estudiar de qué manera actúa la traducción en las secciones de opinión de la prensa española, cómo se utiliza y con qué objetivos. Para ello, nos hemos centrado en una cabecera con amplia repercusión mediática, como es el diario español El País, y en su postura ante un acontecimiento de alcance global como fueron las revueltas árabes que se iniciaron en enero de 2011, también conocidas como la primavera árabe. Partimos del hecho de que las empresas periodísticas, aunque informativas, persiguen objetivos persuasivos e ideológicos y de que los diferentes medios aplican una determinada política de traducción. Nuestra hipótesis de trabajo es que las tribunas traducidas que aparecen en las páginas de opinión cumplen el mismo cometido que el resto de colaboraciones y sirven de apoyo y refuerzo a la línea editorial del periódico. Utilizando una metodología descriptiva (Toury 2004) y la teoría del enfoque (Gitlin 1980), pretendemos analizar el uso que una empresa periodística concreta hace de la traducción con el fin de establecer sus líneas de comportamiento, determinar qué pautas sigue y su incidencia en la cultura receptora. En este sentido, hemos recopilado las tribunas que publicó El País sobre las revueltas árabes a lo largo de sus dos primeros meses. Dado que estos acontecimientos todavía se estaban desarrollando en el momento de llevar a cabo este estudio, hemos tenido que acotar un periodo para nuestro análisis y nos hemos centrado en el periodo comprendido entre el 13 de enero (día en que se publicó la primera de ellas) 
y el 18 de marzo de 2011. Nos detenemos en esta última fecha porque a partir de ese día se produce una inflexión en los acontecimientos: la ONU aprobó una resolución que permitía el uso de la fuerza para imponer una zona de exclusión aérea sobre Libia y la OTAN se prepara para atacar el régimen de Muamar el Gadafi. España participó en esta operación con medios navales y aéreos, y este hecho abre una nueva orientación de las tribunas de opinión que publicó este diario y que pueden ser objeto de otro estudio. Entre el 13 de enero y el 18 de marzo de 2011, El País publicó en total 73 tribunas, de las cuales 47 fueron traducciones.

Hemos estructurado este trabajo de la siguiente forma: en el segundo apartado repasamos brevemente el marco en el que se inserta este estudio. En el tercero, nos ocupamos del análisis descriptivo de las tribunas publicadas en El País y, en el cuarto, sirviéndonos de la teoría del enfoque, profundizamos en los mensajes que recibió la sociedad española a través de este periódico, con una particularidad: la distinción en nuestro análisis entre los discursos locales -los que mantienen los intelectuales españoles invitados a colaborar en las páginas de opinión del periódico-, y los discursos traducidos o globales - procedentes de firmas de prestigio internacionales, igualmente seleccionadas para crear opinión-. Analizamos el uso que se hizo de la traducción para saber por qué se tradujo y qué política de traducción aplica el diario.

\section{Ideología, opinión y traducción en la prensa}

En el actual contexto mediático, con un constante trasvase de información entre culturas, la traducción desempeña un papel cada vez más importante. El caudal informativo a escala global circula en una cantidad que, lejos de disminuir, no deja de incrementarse día tras día. No sólo las noticias, también los artículos de opinión se difunden por todos los países y la prensa los selecciona y los traduce para sus audiencias con una intención específica que obedece a su estrategia empresarial. Todo ello con el objetivo principal de trasmitir una determinada ideología y crear estados de opinión.

Desde diferentes enfoques, numerosos estudios han señalado el importante papel que desempeña la prensa en la transmisión de ideologías. Es el caso de los trabajos de Fowler (1991), Wodak, Cilia et al. (1999) o van Dijk (1998), que parten del análisis del discurso, o los de Aguilera (1990) o Belloc (2007) desde el ámbito periodístico español. La sociología, por su parte, ha estudiado el papel de la prensa escrita, en general, y las secciones de opinión, en particular, a la hora de forjar la opinión pública. Así, trabajos como los de de Miguel Rodríguez (1982), Monzón Arribas (1996), Lippmann (2003), McCombs (2006) o Hernández Sánchez (2008), entre otros muchos, han demostrado la inmensa proyección de la prensa como medio de difusión de ideas.

Los Estudios de Traducción, a su vez, se han ocupado de la utilización de la traducción para la transmisión de ideologías, así como de su papel a la hora de forjar identidades. Buena muestra de ello son los trabajos de Álvarez y Vidal (1996), Baker (2006), Bastin (2008), Calzada Pérez (2003), Cronin (2006) o Venuti (1992). Más recientemente, han analizado cómo se utiliza la traducción en los medios de comunicación (Bielsa y Bassnett 2009, Cortés Zaborras y Hernández Guerrero 2005, Hernández Guerrero 2009 y Valdeón 2010).

Ya en el terreno más específico de la traducción de textos de opinión en la prensa española, varios estudios se han adentrado en este campo desde diferentes perspec- 
tivas. Ramírez (2005), en un volumen colectivo -El texto de opinión de la prensa escrita. Su tratamiento en la traducción-, se ocupa de la traducción al español de esta variedad textual desde un punto de vista discursivo. Se analizan textos de opinión en alemán, francés e inglés, que presentan una serie de rasgos comunes en estas culturas, como son: los mismos objetivos y funciones, su carácter evaluativo y apelativo, y su naturaleza idiolectal. La diferencia entre unas culturas y otras estaría en las convenciones verbales y en lo que García López (2005: 52) denomina «los puntos de interés cultural», es decir, los temas que centran la atención de los diferentes columnistas dentro de una misma cultura.

En Hernández Guerrero (2005) encontramos una caracterización de los diferentes géneros periodísticos y una descripción de cómo se suelen traducir en la prensa española. En lo que respecta a los géneros argumentativos -también denominados géneros de opinión, editorializantes o de solicitación de opinión- los análisis de traducciones muestran que los traductores respetan el estilo del autor y, por lo general, se trata de traducciones relativamente fieles. Sin embargo, como el resto de los géneros periodísticos, no escapan a las transformaciones impuestas por el nuevo medio que las publica, aunque, eso sí, en menor medida que otros géneros periodísticos. Así, los análisis muestran que es poco frecuente que estos textos sufran mutilaciones por motivos de espacio, pero sí experimentan adaptaciones debidas al nuevo receptor, a la nueva situación comunicativa y, por supuesto, a su nuevo canal.

Otros trabajos han ofrecido datos sobre el volumen de traducción en algunos diarios y sobre las lenguas de las que se traduce. Es el caso de la tesis doctoral de González Rodríguez (1999), que presenta la primera aproximación cuantitativa que permite analizar el peso de la actividad traductora en dicho periódico durante un año y ofrece una visión bastante certera de la importancia de la traducción en este medio. Más recientemente, otro trabajo (Hernández Guerrero 2008) se ha ocupado de cuantificar el volumen de traducción de las secciones de opinión de las dos principales cabeceras españolas, El País y El Mundo, durante el año 2004, de establecer en porcentajes de qué lenguas se traduce y de analizar la recepción de estas traducciones. Estos datos se han ampliado de 2004 hasta 2008 en un trabajo posterior (Hernández Guerrero 2009), donde se acuña la denominación de fuentes estables para el material periodístico que se considera como definitivo y se traduce sin modificaciones importantes, y fuentes inestables para ese otro material que se considera materia prima para producir nueva información y que suele experimentar importantes modificaciones en el proceso de traducción. Se establece, además, una relación entre estos dos tipos de fuentes y los géneros periodísticos: los géneros de opinión suelen ser tratados como fuentes estables, mientras que los géneros informativos se consideran como inestables.

Pese a estos enfoques previos, todavía no se ha realizado ningún estudio que aborde el papel que desempeña la traducción en la configuración de los discursos que difunde la prensa española, por qué se utiliza y cómo contribuye a forjar determinadas corrientes de pensamiento en la opinión pública. Nos proponemos, pues, analizar los mecanismos que rigen este proceso y sus implicaciones en una cabecera de prestigio que se sirve sistemáticamente de la traducción: el diario El País. 


\section{Análisis de las tribunas traducidas en el diario El País}

Este análisis se enmarca en la línea de los estudios descriptivos de traducción, cuyo objetivo es describir y explicar los fenómenos de traducción, las traducciones, entendidas estas como hechos culturales, como parte integrante y significativa de la cultura receptora (Toury 2004). Pretendemos, pues, reflejar la realidad de la traducción en un periódico que la utiliza con unos fines específicos, basándonos en el análisis de un corpus de textos de opinión traducidos en un momento histórico concreto -los inicios de la primavera árabe- y atendiendo a las diferentes circunstancias que influyen en el proceso y determinan el producto. Con este fin, abordaremos cuestiones como el estatus del medio, su postura ante los acontecimientos, los autores seleccionados y la procedencia de los originales, quiénes son los traductores y cómo han traducido.

\subsection{El País y la cobertura de la primavera árabe de 2011}

El País es un periódico de pago que pertenece al mayor grupo mediático español, el Grupo PRISA. Con una media de 370.080 ejemplares diarios en 2010, según datos de la Oficina de Justificación de la Difusión (OJD)², es el periódico de información general de mayor difusión de España. A mediados de los años 1990, El País comenzó a ofrecer una edición electrónica en Internet, que a partir de noviembre de 2002 impuso el sistema de pago para acceder a sus contenidos informativos, lo que se tradujo en una disminución drástica de sus visitas. En junio de 2005 El País volvió a ofrecer la mayoría de sus contenidos gratuitamente, situándose en segundo lugar en número de usuarios conectados, por detrás de la edición electrónica del diario $E l$ Mundo, su más inmediato competidor. La situación se invirtió en diciembre de 2010 cuando ComScore, empresa de medición del tráfico en Internet, otorgó el liderazgo de los diarios digitales en España a El País con 2,9 millones de lectores, frente a los 2,6 millones de su competidor ${ }^{3}$, aunque este liderazgo en la red fluctúe según el sistema de medición que se emplee ${ }^{4}$. Tanto en su edición impresa como en la digital, $E l$ País es líder de audiencia, llegando a un considerable número de lectores, lo que le convierte en el periódico español de referencia.

En el terreno ideológico, El País ha sido definido como de tendencia europeísta, situado ideológicamente entre el centro-izquierda y la izquierda y caracterizado por el extenso tratamiento que da, en lo informativo, a las noticias de carácter internacional, de cultura y de economía, además de la información nacional ${ }^{5}$. A través de su línea editorial, se presenta como progresista, abierto, tolerante, con imagen de moderado (Canel 1999). Su sección de opinión es la más nutrida de toda la prensa de prestigio española y suele recoger diariamente tres tribunas de reconocidas firmas nacionales e internacionales, no pertenecientes a la plantilla, que conviven con las columnas de los articulistas que trabajan para el diario. También se incluyen tribunas en otras secciones del periódico (en la sección de internacional, por ejemplo) de manera puntual. El periódico vuelca estas tribunas en la edición digital, lo que da una proyección suplementaria a sus autores.

En enero de 2011, a raíz del inicio en Túnez de las protestas que acabarían con el régimen dictatorial del presidente Zine El-Abidine Ben Alí y que posteriormente se extendieron por todo el norte de África y Oriente Próximo, el diario El País 
comenzó a informar sobre estos acontecimientos bajo la rúbrica Ola de cambio en el mundo árabe. El desenlace es de todos conocido: en apenas dos meses, cayó la dictadura egipcia, comenzó una guerra civil en Libia y las protestas se extendieron por otros países (Yemen, Siria...). Desde el inicio de las revueltas, el diario adoptó una línea editorial de apoyo a estos movimientos, al mismo tiempo que se mostraba crítico con la postura temerosa y expectante de los gobiernos occidentales. Junto a la información puntual de estos acontecimientos, el periódico publicó una serie de tribunas de reconocidas figuras nacionales e internacionales para nutrir a los lectores de argumentos para formarse opinión. Porque más allá de la noticia en sí, ciertos lectores van buscando qué opinar, cuáles son los elementos esenciales para formarse una idea sobre un acontecimiento de actualidad que les llama la atención y del que desean seguir su evolución.

Como ya hemos indicado, hemos tenido que acotar un periodo para nuestro análisis y nos hemos centrado en las tribunas que publicó El País sobre las revueltas árabes durante sus dos primeros meses: desde la primera, publicada el 13 de enero de 2011, hasta la del 18 de marzo del mismo año: un total de 73 tribunas, de las que 26 corresponden a firmas del ámbito hispánico y 47 fueron traducciones. Queda patente, pues, que el diario se sirvió preferentemente de la traducción: las tribunas traducidas representaron un 64,4\% del total, frente al 35,6\% de tribunas locales.

\subsection{Los autores de las tribunas}

Es sabido que la prensa escrita importa textos de una manera selectiva y se inclina por invitar a escribir en sus páginas de opinión a intelectuales, políticos, escritores, etc., siguiendo criterios que generalmente vienen marcados por su línea editorial. Se trata de una realidad apenas velada y que persigue unos fines determinados:

Los editores de los medios de comunicación son los verdaderos intelectuales orgánicos del sistema. Es decir, son los propietarios y los hombres de confianza de las empresas de comunicación los que con su poder nombran directivos de los medios, contratan firmas, señalan las líneas editoriales, mantienen relaciones con los poderes políticos y económicos y construyen los discursos compatibles con una opinión pública que se encargan de vertebrar. Después están los líderes de opinión y los intelectuales que desempeñan el papel de interpretación primaria de los hechos noticiosos, liderando a la opinión pública con sus reflexiones. Estos intelectuales se han constituido en una noocracia, esto es, la clase cultural privilegiada que controla el poder del conocimiento en la red mediática. Esta intelectualidad ejerce su poder impulsando las tendencias y corrientes ya existentes y complaciendo al poder político. La complejidad de las grandes decisiones económicas, políticas, científicas, militares, etc. impide que el público esté en condiciones de adoptar una opinión consistente acerca de ellas. Son los líderes de opinión y los intelectuales, en cuanto dirigentes de la opinión pública, quienes se la proporcionan a través de los medios de comunicación de masas. (Hernández Sánchez 2008: 73)

La postura que adopta cada medio de comunicación se refleja en la selección del material publicado, la ausencia de determinadas noticias, la orientación que reciben las informaciones, etc. Actúan de igual manera en el caso de los textos que se van a traducir. Así, del mismo modo en que se aplica una política de opinión, podemos observar que, en el caso de El País, ésta se apoya, a su vez, en una política de traducción, de tal manera que se traduce con una finalidad específica. Este hecho queda patente en el elevado número de tribunas traducidas, antes señalado. 
Para la transmisión ideológica de una determinada corriente de pensamiento resulta crucial la elección de la cantera de líderes de opinión e intelectuales que con sus artículos van a nutrir las páginas del medio. Nuestro análisis de las tribunas de El País muestra que, durante el periodo analizado, el diario ha recurrido mayoritariamente a su cantera de firmas habituales. Tanto las 26 tribunas escritas originalmente en español, como las 47 que se han traducido proceden de colaboradores que publican con regularidad en el diario. Eso explica que algunos de ellos sean autores de varias tribunas.

En el caso de las 26 tribunas españolas, el elenco de firmas está formado por un grupo variopinto de prestigiosos escritores, periodistas, investigadores, etc. Es el caso del escritor Juan Goytisolo, autor de tres de estas tribunas; José María Ridao, escritor, diplomático y miembro del consejo editorial del diario, quien firma otras dos, al igual que la periodista cubana Yoani Sánchez. Dos más son obra de Jordi Vaquer, director de la Fundación CIDOB, centro de investigación en relaciones internacionales. Son, igualmente, colaboradores habituales los escritores Mario Vargas Llosa, Antonio Elorza y Jorge Volpi; el historiador Ángel Viñas; Javier Valenzuela, que trabaja en el área de Opinión del diario; el diputado socialista Emilio Menéndez del Valle y los arabistas Gema Martín Muñoz y Bernabé López García.

El resto de autores (Francis Ghilès, Nicolás Sartorius, Vicente Palacio, Carlos Carnero, Tomás Jiménez Araya, Rafael Díaz Salazar, Enrique Gil Calvo, Diego López, Javier Solana y Mariano Aguirre) publica de forma más esporádica en este diario.

Si el plantel de firmas del ámbito hispánico es relevante, las firmas internacionales no se quedan a la zaga. Las 47 tribunas traducidas corresponden a destacados intelectuales que, en su mayor parte, publican con regularidad en las páginas de $E l$ País, y, como en el caso anterior, firman varios trabajos. Es el caso del profesor de origen argelino Sami Naïr, con ocho tribunas traducidas; Bernard-Henri Lévy, con seis; Timothy Garton-Ash, con cinco; Jean-Marie Colombani, con cuatro o Shlomo Ben Ami, con dos. Otras figuras frecuentes en el periódico firman una tribuna, como es el caso del disidente iraní Ramin Jahanbegloo, el filósofo esloveno Slavoj Zizek, el historiador israelí Ilan Pappé, el historiador británico Paul Kennedy, el profesor estadounidense Norman Birnbaum o el político alemán Joschka Fischer. Otros autores reproducidos son: André Glucksmann, Alain Touraine, Tariq Ramadan y Olivier Roy.

Junto a estos intelectuales -de renombre internacional-, El País traduce por primera vez a otras firmas, que, salvo el escritor estadounidense Andrew Solomon, son intelectuales de origen árabe: el escritor egipcio Alaa Al Aswany, el escritor marroquí Abdellatif Laâbi, el escritor argelino Yasmina Khadra, el profesor de origen egipcio Omar Ashour, el escritor libio Hisham Matar, la presidenta de la asociación francesa EuropAnous Djémila Boulasha, el político jordano Marwan Muasher, el escritor marroquí Driss Ksikes y el escritor libio-británico Alaa al Ameri. De esta forma da voz a los intelectuales árabes y, al mismo tiempo, ofrece una imagen de pluralidad que contrarresta, de algún modo, el mayor peso que tienen las tribunas de líderes de opinión occidentales.

Es difícil generalizar ante un elenco de intelectuales tan amplio, pero resulta evidente, por la conocida trayectoria de muchos de ellos, que su posicionamiento ideológico está próximo a la línea editorial progresista del diario. De hecho, algunas de estas firmas trabajan para el periódico, como José María Ridao, miembro del 
consejo editorial, Javier Valenzuela, del área de Opinión, o Jean-Marie Colombani, miembro del consejo de administración.

En otros casos, se trata de líderes de opinión con una enorme proyección nacional e internacional, con visiones propias de la realidad, y que tienen carta blanca a la hora de escribir, más aún cuanto mayor es el peso de la firma. Este hecho salta a la vista en casos concretos como el del escritor Juan Goytisolo, muy crítico con la civilización occidental, a la que contempla desde una óptica periférica; o Mario Vargas Llosa, próximo a posturas ideológicas liberales, cuya tribuna, bajo la rúbrica Piedra de toque, se publica en más de veinte medios de comunicación de variada línea editorial; o Bernard-Henri Lévy, cuyos postulados (especialmente su postura pro israelí) no siempre son coincidentes con los de El País ${ }^{6}$.

Esta pretendida pluralidad permite que haya opiniones en líneas diferentes para poner de relieve, como una especie de coartada, la liberalidad del medio a la hora de admitir puntos de vista contrapuestos a su propia ideología.

\subsection{Procedencia de los originales}

Nuestra búsqueda de los originales de las 47 tribunas traducidas ha tropezado con bastantes escollos. La mayor dificultad para llevar a cabo esta tarea es que el periódico no indica normalmente las fuentes de las que se sirve y la mayor parte de las traducciones se presenta sin una información paratextual completa que permita poder identificar la procedencia de los originales. Además, los textos traducidos adoptan generalmente un formato distinto al del texto de partida y en ocasiones presentan modificaciones que dificultan la localización e identificación de los originales (por ejemplo, el cambio del título). Por todas estas razones, la labor de localización de los originales no ha estado exenta de dificultad.

El País incluye en todas sus tribunas un pie de texto que proporciona información sobre el autor. En el caso de las traducciones incluye, además, cierta información paratextual, que no es sistemática, y que en las tribunas analizadas básicamente consiste en:

1) solo el nombre del traductor;

2) el nombre del traductor junto con el del propietario de los derechos del original;

3) el nombre del traductor, el del propietario de los derechos del original e indicación de la lengua desde la que se ha traducido.

Así, el pie de texto más completo que hemos encontrado en las tribunas analizadas correspondería al tipo (iii) y sería similar al del siguiente ejemplo extraído de una de estas traducciones:

(1) Joschka Fischer fue ministro de Asuntos Exteriores, vicecanciller de Alemania y líder de su Partido Verde. ( ) Project Syndicate / Institute for Human Sciences, 2011. Traducido del inglés por David Meléndez Tormen.

(Fischer, 13 marzo 2011) ${ }^{7}$

Lo más habitual, sin embargo, es que el pie de texto solo recoja el nombre del autor de la traducción, como se observa en los porcentajes que arroja la siguiente tabla: 
TABLA 1

Información paratextual en las tribunas analizadas

\begin{tabular}{|l|c|c|}
\hline Datos en el pie de texto & Tribunas & \% \\
\hline Nombre del traductor & 39 & 83 \\
\hline Nombre del traductor + copyright & 5 & 10,7 \\
\hline Nombre del traductor + copyright + lengua & 2 & 4,2 \\
\hline Sin datos & 1 & 2,1 \\
\hline
\end{tabular}

El nombre del traductor se convierte, por tanto, en el elemento paratextual determinante que permite identificar estos textos como traducciones. El periódico lo indica en la casi totalidad de las tribunas analizadas (sólo en un caso no lo hace). Los lectores atentos saben, pues, que acceden a traducciones.

En lo que respecta a su procedencia, han llegado al periódico por distintas vías: unos han sido adquiridos a servicios internacionales de distribución de artículos, como Tribune Media Services o Project Syndicate; otros proceden de intelectuales a los que el periódico solicita habitualmente sus artículos (Sami Naïr, Bernard-Henri Lévy, Jean-Marie Colombani, Timothy Garton-Ash...); y, por último, están las firmas a las que recurre de manera más esporádica (Jean Daniel, Alain Touraine...), como cuando interesa recabar opiniones sobre un determinado acontecimiento (Alaa Al Aswany, Abdellatif Laâbi, Driss Ksikes...). En las traducciones analizadas, la procedencia de los originales se reparte de la siguiente forma:

TABLA 2

Procedencia de los originales en las tribunas analizadas

\begin{tabular}{|l|l|l|}
\hline & Tribunas & \% \\
\hline Firmas habituales & 25 & 53,2 \\
\hline Firmas no habituales & 14 & 29,8 \\
\hline Servicios de distribución & 8 & 17 \\
\hline
\end{tabular}

En lo referente a la lengua de los originales, se han traducido mayoritariamente del francés y el inglés. En concreto, hay 26 traducciones del francés (el 55,3\%) y 21 del inglés (el 44,7\%). Estos porcentajes no son los habituales, lo normal en la sección de Opinión de El País es que se traduzca mucho más del inglés ${ }^{8}$. Explica esta variación que el foco de los acontecimientos esté en el Mediterráneo y el periódico haya recurrido a los analistas franceses, conocedores de la zona, que suelen publicar en sus páginas (Sami Naïr, Bernard-Henri Lévy, Jean Daniel, Alain Touraine...) y haya solicitado opinión a intelectuales árabes que se expresan en francés (Abdellatif Laâbi, Driss Ksikes, Yasmina Khadra...).

\subsection{Los traductores}

Para su sección de opinión El País recurre siempre a traductores autónomos, que no pertenecen a la plantilla del periódico. La mayoría de las traducciones analizadas (41 tribunas) las firman: Juan Ramón Azaola, Jesús Cuellar Menezo, María Luisa Rodríguez Tapia, Martí Sampons y José Luis Sánchez-Silva. Se trata de profesionales de la traducción con una amplia experiencia, que traducen tanto para la prensa como 
para otros sectores, como el editorial. Sus firmas figuran regularmente en las traducciones de la sección de opinión de este periódico. La traducción del artículo del historiador israelí afincado en Gran Bretaña Ilan Pappé es, sin embargo, obra de Pilar Salamanca. Se trata de una única traducción, pero la comentamos porque esta escritora y traductora firma siempre los trabajos de Pappé que se traducen en este diario, lo cual denota cierta especialización que se extiende al resto de los traductores mencionados (así, por ejemplo, las traducciones de Bernard-Henri Lévy las suele hacer José Luis Sánchez-Silva y las de Timothy Garton Ash, María Luisa Rodríguez Tapia). Además de estos profesionales, figuran David Meléndez Tormen y Carlos Manzano, traductores al español en Project Syndicate, un servicio de distribución de artículos del que se nutre El País y que ofrece sus artículos ya traducidos a diferentes lenguas. En una única tribuna se menciona a News Clips, el nombre de una agencia de traducción con la que suele trabajar este diario.

Los traductores autónomos antes mencionados realizan, pues, el grueso de las traducciones que se publican en la sección de Opinión de El País. Esta decisión pone en evidencia que el periódico quiere traducciones de calidad para unos textos firmados por figuras de prestigio internacional, que van destinados a los lectores de dicha sección, exigentes y cultos. Estos profesionales reciben los encargos directamente y cuentan de media con un plazo de dos días para traducir las tribunas. Pero no es extraño que haya urgencias (un acontecimiento inesperado, por ejemplo) y, entonces, es corriente que dispongan de solo cuatro o cinco horas de tiempo para realizar su trabajo. De todas formas, hay que tener presente que estas traducciones suelen ser revisadas en el periódico y pasan por diferentes manos en su proceso de edición, por lo que algunos de los cambios finales que se observan en los textos publicados no son decisiones de los traductores.

\subsection{Análisis comparativo}

La comparación de originales y traducciones se ha llevado a cabo sobre 39 textos de los 47 que componen el corpus, debido a que no hemos podido encontrar los originales en ocho casos. En todos los textos analizados hemos comprobado que nos hallamos ante traducciones en el sentido estricto de la palabra, es decir, textos que reproducen el contenido de los originales, hecho ya constatado en otros trabajos sobre textos de opinión, mencionados en el apartado 2. Su estatus, además, es el de una traducción, pues presentan marcas que permiten reconocerlos como tales y que así se reciban en el nuevo sistema cultural en el que funcionan. Influye en ello que los originales sean artículos firmados, con unos determinados derechos de autor que restringen la libertad de acción del periódico. Por tanto, estos originales responden a lo que hemos denominado fuentes estables, es decir, material periodístico que se considera como definitivo y se traduce sin modificaciones importantes. El hecho de que muchas de estas tribunas de El País se publiquen en otros medios de comunicación nos ha ayudado bastante en la localización de los originales ${ }^{10}$.

El análisis comparativo muestra que, en general, estamos ante traducciones de gran calidad, donde apenas se aprecian errores. Son textos periodísticos, pero pertenecientes al género argumentativo y esto influye en el método de traducción utilizado $^{11}$ : se sigue de cerca el estilo del autor pero se busca preferentemente la aceptabilidad (Toury 2004), es decir, se privilegian las normas de la cultura receptora. 
Además, estas traducciones se adaptan, durante su fase de edición, a la norma periodística que marca el Libro de estilo de El País y su aspecto formal es el mismo que el del resto de las tribunas. Su recepción, asimismo, es similar, y para un grupo importante de lectores pasa totalmente desapercibida la labor de mediación de la que han surgido.

Del análisis también se desprende que las principales técnicas de traducción que observó Vuorinen (1997) en la transmisión internacional de noticias (adición, omisión, síntesis y reorganización) no se aprecian en la transmisión internacional de artículos de opinión, al menos en el caso analizado. No hay síntesis ni reorganización del contenido de los textos traducidos; las omisiones encontradas son muy escasas y no parecen responder a motivos de censura ideológica, sino más bien a cuestiones de espacio y, por ello, suelen producirse en la parte final de los textos, un claro indicador de las limitaciones propias del formato periodístico. En lo que respecta a las adiciones, tampoco se observa un empleo significativo, como sí ocurre en las noticias traducidas, donde es frecuente que haya que actualizar la información, contextualizarla o explicarla (Hernández Guerrero 2006). En las tribunas traducidas, las únicas intervenciones encontradas responden a aclaraciones de algún elemento cultural de tipo explicativo, como el del siguiente ejemplo:

(2) Les guerres du pain sont nombreuses dans tous les pays. En France, elles ont déclenché les jacqueries que l'on sait.

$($ Daniel 2011) 12

En todos los países ha habido guerras del pan. En Francia desencadenaron las revueltas campesinas conocidas como jacqueries.

(Daniel 2011, traducido por Sánchez-Silva) ${ }^{13}$

Donde sí se observan cambios significativos es en los títulos, segmentos que incitan a leer el texto y poseen una clara función identificadora. Para Núñez Ladevéze (1991: 224) el tipo de titular que se emplea en los textos de opinión funciona como un rótulo para la argumentación que desarrollan, de la que enuncian el tema. En español, suelen ser cortos y sugestivos, pues en estos artículos el gancho es el nombre del autor: se leen más por la firma que por lo atractivo del título. En el corpus analizado, se puede apreciar que en la mitad de los casos (20 de los artículos) se ha llevado a cabo una traducción literal del título del original; en 9 casos el título del original se ha reducido, bien eliminando algún segmento, bien resumiéndolo; y, por último, en 10 ocasiones se ha optado por un nuevo título para la tribuna traducida. Este cambio responde a razones diversas; en algunos casos se observa un afán de suavizar títulos demasiado comprometedores y, en otros, se ha preferido crear un nuevo título a partir de frases extraídas del propio texto ${ }^{14}$.

\section{Discursos locales versus discursos traducidos}

Siguiendo con nuestro análisis, en este apartado pretendemos establecer qué corrientes de opinión se transmitieron a la sociedad española a través de El País, distinguiendo entre discursos locales -los que mantuvieron los intelectuales españoles invitados a colaborar en las páginas de opinión del periódico-, y discursos globales o traducidos -los que se tradujeron de firmas de prestigio internacionales, igualmente seleccionadas para crear opinión-. Nos hemos servido de la teoría del enfoque ( fra- 
ming), entendido como patrones de conocimiento, interpretación y presentación, de selección, énfasis y exclusión, con los que se organiza el discurso de los medios (Gitlin 1980). Una buena parte de la investigación sobre framing considera que los enfoques son fundamentalmente ideológicos. Estos estudios comenzaron poniendo el acento en los factores individuales para explicar las diferencias en los enfoques. Sin embargo, en los últimos años nuevas investigaciones ven las causas de los enfoques en la naturaleza compleja del proceso de producción periodística. Consideran que los factores individuales no son más que una parte del conjunto de elementos que intervienen en la mediación de la información y hay que tener en cuenta otros factores como los sociológicos u organizativos. Los enfoques dependen, pues, de factores individuales, pero también de la infraestructura del medio, de quiénes son sus propietarios, y de otros elementos externos como los poderes políticos y económicos, la competencia y la audiencia (Shoemaker y Reese 1991). Adoptamos, pues, este último planteamiento que concibe a los medios como una maquinaria que procesa, analiza e interpreta, dando como resultado final un relato. No podemos olvidar que los medios de comunicación crean y conforman la opinión pública; actúan difundiendo determinados mensajes. A través de las secciones de opinión se lleva a cabo una auténtica labor de persuasión ideológica, mediante la difusión intencionada de determinados enfoques que transmiten corrientes de pensamiento.

El análisis se centra en las tribunas publicadas durante los dos primeros meses de la primavera árabe, cuando se produce la caída de las dictaduras tunecina y egipcia, y comienzan las revueltas en Libia, duramente reprimidas por Gadafi. En ese periodo, El País recurrió abundantemente a la traducción, y las tribunas del diario difundieron unos determinados enfoques centrados en los siguientes temas: la postura de Occidente (representado por EEUU y Europa) ante las revueltas árabes, el protagonismo de la juventud y las nuevas tecnologías, el modelo turco, la postura israelí, el caso de Marruecos (la prensa española presta gran atención a todo lo relacionado con el vecino del Sur) y, por último, la guerra civil en Libia. En los siguientes apartados desglosamos los enfoques presentes en las tribunas analizadas en torno a esos focos de interés, distinguiendo entre discursos locales y discursos traducidos.

\subsection{Enfoques presentes en los discursos locales}

1) Occidente ante las revueltas árabes

- Crítica a su reacción timorata, considerada como vergonzosa.

- Crítica a su hipocresía: ha estado apoyando a estas dictaduras en lugar de defender la democracia.

- Debe comprometerse en la defensa de estos movimientos democráticos.

- Debe auxiliar, política y económicamente, a las nuevas democracias del Mediterráneo.

2) Protagonismo de la juventud y las nuevas tecnologías

- El uso que han hecho los jóvenes de los móviles e Internet ha sido determinante en el éxito de las revueltas.

3) El modelo turco

- Turquía puede ser un modelo de democracia válida para los musulmanes por su equilibrio entre laicismo e islam.

- Es un error hacer de Turquía un modelo: supone asumir que los ciudadanos árabes están incapacitados por la religión para disfrutar de un auténtico régimen de libertades. 
4) Marruecos

- Necesita un cambio de rumbo que instaure la separación de poderes y la protección de las libertades.

5) La postura israelí

- Críticas a Israel por considerar que la estabilidad y la seguridad de la región pasan por el mantenimiento de las dictaduras.

6) Guerra civil en Libia

- Críticas y descalificaciones a la figura de Gadafi.

- Advertencias sobre el posible caos tras la caída de Gadafi.

- La ONU debe defender a la población civil libia de los ataques de Gadafi.

\subsection{Enfoques presentes en los discursos traducidos}

1) Occidente ante las revueltas árabes

- Crítica a su reacción timorata, considerada como vergonzosa.

- Crítica a su hipocresía: ha estado apoyando a estas dictaduras en lugar de defender la democracia.

- Crítica a los medios de comunicación occidentales por potenciar la islamofobia.

- Debe comprometerse en la defensa de estos movimientos democráticos.

- Debe auxiliar, política y económicamente, a las nuevas democracias del Mediterráneo.

- Hay que estar prevenidos ante el peligro de una deriva integrista.

2) Protagonismo de la juventud y las nuevas tecnologías

- La primavera árabe surge de una juventud laica que quiere democracia y libertad.

- Su uso de las nuevas tecnologías ha sido determinante en el éxito de las revueltas.

3) El modelo turco

- Turquía puede ser un modelo de democracia válida para los musulmanes por su equilibrio entre laicismo e islam.

4) Marruecos

- Necesita un cambio de rumbo que instaure la separación de poderes y la protección de las libertades.

5) La postura israelí

- Críticas a Israel por considerar que la estabilidad y la seguridad de la región pasan por el mantenimiento de las dictaduras.

- Israel debe revisar su estrategia y apoyar la creación de democracias en la zona.

- El apoyo de Obama a las revueltas marca un distanciamiento con respecto a Israel.

6) Guerra civil en Libia

- Críticas y descalificaciones a la figura de Gadafi.

- Advertencias sobre el posible caos tras la caída de Gadafi.

- La ONU debe defender a la población civil libia de los ataques de Gadafi.

- Gadafi debe ser acusado por crímenes contra la humanidad.

- Es necesario crear una zona de exclusión aérea sobre Libia.

- No se debe crear una zona de exclusión aérea sobre Libia.

- Posiciones a favor de una intervención militar en Libia.

\subsection{Enfoques, corrientes de opinión y línea editorial}

La confrontación de discursos locales y traducidos pone de relieve que existen bastantes puntos en común. Prácticamente se puede afirmar que los enfoques presentes en los discursos traducidos retoman y amplían los defendidos en los discursos locales, con muy pocos matices. Se aprecia un mayor número de enfoques en las tribunas traducidas, algo lógico al ser más numerosas. En general, las opiniones vertidas se 
muestran coincidentes con la línea editorial del diario, que mostró su apoyo a la ola de cambio que suponía la primavera árabe y se mostró crítico con la respuesta tibia de Occidente. Esta coincidencia se extiende a otros focos de interés. Así, por ejemplo, los enfoques críticos con la postura israelí coinciden con la línea editorial habitual que mantiene el diario. Influye en ello que las únicas figuras israelíes invitadas a opinar -Shlomo Ben Ami e Ilan Pappé- mantengan una actitud bastante crítica hacia la política de su país. En este mismo sentido, los enfoques a favor de una intervención militar en Libia se muestran coincidentes con la postura de El País en sus editoriales ${ }^{15}$.

El análisis pone de manifiesto que este pretendido lugar de interacción social abierto al intercambio de opiniones, que serían las tribunas de El País, se revela más bien como un foro de debate donde el medio ejerce el control de las opiniones; no lo hace de un modo directo, es decir, mediante la manipulación del contenido de los artículos, sino indirecto, controlando quién participa en el foro. Ello no es óbice para que el medio cuide las apariencias y pretenda mantener una imagen de pluralismo; lo hace consintiendo la presencia de contraopiniones, ya que no hay nada más plural que el debate público basado en el desacuerdo y en la discusión de un asunto. El recurso a las contraopiniones se observa tanto en el discurso local como en el traducido. En el primero, se aprecia en los enfoques sobre el modelo turco: algunos analistas lo consideran un modelo válido para los árabes por su equilibrio entre laicismo e islam, mientras que para otros supone asumir que estos están incapacitados por su religión para disfrutar de un auténtico régimen de libertades. En el discurso traducido las encontramos, igualmente, en las opiniones sobre Libia: algunos analistas se inclinan por la creación de una zona de exclusión aérea y otros manifiestan su oposición.

En definitiva, el medio, con la excusa de proporcionar un canal a través del cual los actores pueden cruzar sus mensajes, refrenda sus propios puntos de vista a través de la selección de las voces que opinan y se asegura, así, de que a su audiencia lleguen unas determinadas corrientes de opinión.

\section{Conclusiones}

El fenómeno de la traducción periodística está vinculado a instituciones sociales -los periódicos, en este caso-, que son las que determinan la selección, producción y distribución de la traducción. Esto implica una política de traducción concreta, que establece los mecanismos que regulan el funcionamiento y los fines de la traducción. Esta perspectiva presenta interesantes implicaciones desde el punto de vista periodístico, traductológico y sociológico.

Sirviéndonos de un acontecimiento de alcance mundial, como la primavera árabe, y centrándonos en un corpus de textos extraídos de una cabecera emblemática, el diario español El País, hemos analizado de qué manera actúa la traducción en las secciones de opinión de la prensa, cómo se utiliza y con qué objetivos. Con la opinión, conduce, dirige y se expresa el propio medio, con su misma voz y con otras que representan el conjunto social. El periódico abre sus tribunas a importantes personalidades de ámbito local y global, y estas últimas llegan a la nueva audiencia a través de la traducción. Estos artículos interactúan con el resto de la opinión que publica el medio (columnas, editoriales...) y contribuyen a difundir y uniformizar ciertas corrientes de pensamiento entre la colectividad. Su influencia es grande y se basa en el prestigio de las firmas seleccionadas, líderes de opinión que gozan de autoridad. 
Nuestro análisis viene a confirmar la hipótesis de partida: las tribunas traducidas que se publican en las secciones de opinión cumplen el mismo cometido que el resto de tribunas y sirven de apoyo y refuerzo a la línea editorial del periódico. Detrás de cada empresa de comunicación hay un potente grupo económico y/o ideológico que defiende unos intereses particulares, que son la razón última de su existencia y el elemento central de su estrategia empresarial. El País sigue una política de opinión que se apoya fuertemente, a su vez, en una política de traducción, de tal manera que se traduce con una finalidad específica: reforzar la línea editorial del medio con la opinión de voces internacionales de contrastada autoridad. Cuanto mayor es la solvencia de la firma, el medio se ve más legitimado y más convencen sus argumentos. Esto no es óbice para que, en ocasiones, permita que se deje oír alguna voz discordante que opine de modo diferente, pero este hecho, más que torpedear su línea editorial, lo que hace es reforzar su imagen de pluralidad ideológica. Desde esta perspectiva, el medio deja de ser un foro de debate público neutral para convertirse en un cauce de expresión controlado, que redunda en sus propios puntos de vista y muestra apoyos a políticas muy determinadas. En este contexto, la traducción desempeña una función sustancial como instrumento que sirve a los intereses de la empresa periodística, utilizado para consolidar su línea editorial.

\section{AGRADECIMIENTOS}

Queremos agradecer a María Luisa Rodríguez Tapia que haya resuelto nuestras dudas en la elaboración del apartado 3.4.

\section{NOTAS}

1. López de Zuazo Algar, Antonio (1990): Diccionario de periodismo. Madrid: Pirámide. Martínez de Sousa, José (1992): Diccionario de información, comunicación y periodismo. Madrid: Paraninfo.

2. Oficina de Justificación de la Difusión. Consultado el 5 de mayo de 2011, <http://www.ojd.es/Introl/ Portal/publicacion_detalle/_LX1O_Pr-rb_siYZ0_A6y71P4ZANY9Afh\#>.

3. Diario El País. Consultado el 5 de mayo de $2011<$ http://elpais.com/diario/2011/01/19/ radiotv/1295391602_850215.html>.

4. Anónimo (25 de mayo 2011): Todos los medidores certifican el sólido liderazgo de ELMUNDO. es. El Mundo. Consultado el 27 de abril de 2011, <http://www.elmundo.es/accesible/elmundo/ 2011/03/25/comunicacion/1301050537.html>.

5. Anónimo (2011): El País. Consultado el 5 de mayo de 2011, <http://es.wikipedia.org/wiki/El_ $\mathrm{Pa} \% \mathrm{C} 3 \%$ ADs\#Ideolog.C3.ADa>.

6. De hecho, la defensora del lector se ha visto obligada a aclarar la postura del diario ante las quejas de numerosos lectores por las opiniones del filósofo francés: «La discrepancia es algo consustancial al género de opinión. De hecho, casi un tercio de las quejas y llamadas que recibo son de lectores que discrepan del contenido de alguna columna, viñeta o artículo. El autor está amparado por la libertad de expresión y el lector por el derecho a ejercer su crítica, con lo que habría poco más que añadir en este caso, excepto dejar constancia del enfado de los lectores. [...] Si bien es cierto que cualquier autor puede reclamar el derecho a seleccionar los datos y hacer la interpretación que crea conveniente, el diario también puede considerar que un artículo con carencias en el respeto a los hechos probados no alcanza la calidad mínima necesaria para ser publicado. La sección de Opinión somete a un severo escrutinio los artículos que se publican y muchos son rechazados por esa razón. En el caso de Lévy, sin embargo, concurre una circunstancia especial. Es uno de esos colaboradores de gran proyección internacional que escriben amparados por contratos que excluyen la posibilidad de discutir el contenido, pues sus artículos se publican simultáneamente en diferentes medios».

Pérez Oliva, Milagros (13 junio 2010): Israel y Palestina: el poder de la opinión. El País. Consultado el 21 de marzo de 2011, <http://elpais.com/diario/2010/06/13/opinion/1276380005 _850215.html>. 
7. Fischer, Joschka (13 marzo 2011): El despertar de Oriente Próximo. El País. Consultado el 21 de marzo de 2011, <http://elpais.com/diario/2011/03/13/opinion/1299970805_850215.html>.

8. Los datos correspondientes a los años 2004, 2005, 2006, 2007 y 2008 muestran como en la sección de opinión de este diario se traduce mayoritariamente del inglés (Hernández Guerrero 2009: 115).

9. Project Syndicate. Consultado el 5 de mayo de 2011, <http://www.project-syndicate.org>.

10. El caso más representativo tal vez sea el de Bernard-Henri Lévy: la tribuna que publica en El País también se puede leer en francés en Le Point y traducida al inglés en The Huffington Post o en el diario israelí Haaretz, entre otros. Algo parecido ocurre con los artículos distribuidos por los syndicates; se venden en inglés a escala global y son traducidos a las lenguas de los medios que deciden publicarlos. Así, la tribuna de Olivier Roy, distribuida por Tribune Media Services, se publicó en The New York Times y en El País se tradujo del inglés. Otros syndicates, como Project Syndicate, ofrecen sus artículos ya traducidos al español.

Roy, Olivier (21 enero 2011): Where Were the Tunisian Islamists? The New York Times. Consultado el 21 de marzo de 2011, <http://www.nytimes.com/2011/01/22/opinion/22iht-edroy22.html?_r=0>. Roy, Olivier (5 febrero 2011): ¿Dónde han ido a parar los islamistas? (Traducido por Juan Ramón Azaola) El País. Consultado el 21 de marzo de 2011, <http://elpais.com/diario/2011/02/05/internacional/1296860407_850215.html>.

11. Siguiendo la propuesta de Hurtado Albir (2001: 249), utilizamos el término método de traducción en el sentido de "opción global que recorre todo el texto", distinto a técnica de traducción, «aplicación concreta visible en el resultado, que afecta a zonas menores del texto».

12. Daniel, Jean (19 enero 2011): Tunisie: l'espoir. Le Nouvel Observateur. Consultado el 30 de abril de 2011, <http://jean-daniel.blogs.nouvelobs.com/archive/2011/01/19/1-espoir.html>.

13. Daniel, Jean (23 enero 2011): Túnez, la esperanza. (Traducido por José Luis SánChez-Silva) El País, <http://elpais.com/diario/2011/01/23/opinion/1295737211_850215.html>.

14. El procedimiento empleado en estos casos consiste en no traducir el título y crear uno nuevo a partir de fragmentos extraídos del propio texto. Así, por ejemplo, en el texto de Žižek (1 febrero 2011), vemos cómo el título original "Why fear the Arab revolutionary spirit?" cambia a "Caos bajo los cielos: qué magnífica situación”, inspirado en este fragmento del texto: «Hoy día, el lema de Mao Zedong resulta más pertinente que nunca: "bajo los cielos hay caos: qué magnífica situación”». ŽIžEK, Slavoj (1 febrero 2011): Why fear the Arab revolutionary spirit? The Guardian. Consultado el 5 de mayo 2011, <http://www.theguardian.com/commentisfree/2011/feb/01/egypt-tunisiarevolt $>$.

ŽIŽEK, Slavoj (3 febrero 2011): Caos bajo los cielos: qué magnífica situación. (Traducido por Jesús Cuéllar Menezo) El País. Consultado el 5 de mayo 2011, <http://elpais.com/diario/2011/02/03/ opinion/1296687604_850215.html>.

15. Véase, por ejemplo, el editorial del 26 de febrero de 2011: "Libia se desangra".

EDITORIAL (26 febrero 2011): Libia se desangra. El País. Consultado el 5 de mayo 2011, <http:// elpais.com/diario/2011/02/26/opinion/1298674801_850215.html>.

\section{REFERENCIAS BIBLIOGRÁFICAS}

Aguilera, Octavio (1990): Las ideologías en el periodismo. Madrid: Paraninfo.

Álvarez, Román y Vidal, María Carmen, eds. (1996): Translation, power, subversion. Philadelphia: Multilingual Matters.

BAKER, Mona (2006): Translation and conflict: a narrative account. London/New York: Routledge.

BAStin, Georges L. (2008): La traducción y la conformación de la identidad latinoamericana. (Dossier). TRANS, Revista de Traductología. 12:11-14.

Belloc, Hilaire (2007): La prensa libre: ensayo sobre la manipulación de las noticias y de la opinión pública, y sobre cómo contrarrestarla. Granada: Nuevo Inicio.

Bielsa, Esperança y Bassnett, Susan (2009): Translation in global news. London/New York: Routledge.

Calzada PÉrez, María, ed. (2003): Apropos of ideology. Manchester: St. Jerome.

Canel, María José (1999): El País, ABC y El Mundo: tres manchetas, tres enfoques de las noticias. ZER. 6:99-119.

Cortés Zaborras, Carmen y Hernández guerrero, María José, eds. (2005): La traducción periodística. Cuenca: Universidad de Castilla La Mancha. 
Cronin, Michael (2006): Translation and identity. London/New York: Routledge. De Miguel Rodríguez, Amando (1982): Sociología de las páginas de opinión. Barcelona: A.T.E. FOWLER, Roger (1991): Language in the news, discourse and ideology in the press. London: Routledge.

GARCía LóPEZ, Rosario (2005): El texto de opinión francés. El artículo o comentario: perspectiva traductológica. In: Ana Sofía Ramírez, ed. El texto de opinión en la prensa escrita. Su tratamiento en la traducción. Las Palmas de Gran Canaria: Servicio de Publicaciones de la Universidad de Las Palmas de Gran Canaria, 51-61.

Giturn, Todd (1980): The whole world is watching: Mass media in the making and unmaking of the new left. Berkeley: University of California Press.

González Rodríguez, Antonio (1999): La traducción en la prensa: "El País, 1995.” Tesis de doctorado. Madrid: Universidad Complutense. Consultado el 4 de marzo de 2010, <http:// www.ucm.es/eprints/3989/>.

Hernández Guerrero, María José (2005): La traducción de los géneros periodísticos. In: Carmen Cortés Zaborras y María José Hernández guerrero, eds. La traducción periodística. Cuenca: Universidad de Castilla La Mancha, 89-133.

Hernández Guerrero, María José (2006): Técnicas específicas de la traducción periodística. Quaderns. Revista de Traducció. 13:125-139.

Hernández Guerrero, María José (2008): Los artículos de opinión traducidos en la prensa escrita: el trasvase transcultural de la opinión. In: María José Hernández guerrero y Salvador peña martín, eds. La traducción, factor de cambio. Berna: Peter Lang, 93-113.

Hernández Guerrero, María José (2009): Traducción y periodismo. Berna: Peter Lang.

Hernández Sánchez, Alfredo (2008): Sociología de la opinión pública. Valladolid: Universidad de Valladolid.

Hurtado Albir, Amparo (2001): Traducción y traductología. Madrid: Cátedra.

Lippmann, Walter (2003): La opinión pública. (Traducido por Blanca Guinea) Madrid: Langre.

Mcсомвs, Maxwell (2006): Estableciendo la agenda. El impacto de los medios en la opinión pública y el conocimiento. (Traducido por Óscar Fontrodona) Barcelona: Paidós.

Monzón Arribas, Cándido (1996): Opinión pública, comunicación y política: la formación del espacio público. Madrid: Tecnos.

NúÑez Ladevéze, Luis (1991): Manual para periodismo. Barcelona: Ariel.

Ramírez, Ana Sofía, ed. (2005): El texto de opinión en la prensa escrita. Su tratamiento en la traducción. Las Palmas de Gran Canaria: Servicio de Publicaciones de la Universidad de Las Palmas de Gran Canaria.

Shoemaker, Pamela y Reese, Stephen (1991): Mediating the message. Theories of influences on mass media content. New York: Longman.

Toury, Gideon (2004): Los estudios descriptivos de traducción y más allá. Metodología de la investigación en Estudios de Traducción. (Traducido por Rosa RabadÁn y Raquel MERINo) Madrid: Cátedra.

VAldeÓN, Roberto A., ed. (2010): Translating information. Oviedo: Universidad de Oviedo.

VAN DijK, Teun (1998): Ideología: un enfoque multidisciplinario. (Traducido por Lucrecia Berrone) Barcelona: Gedisa.

van Dijk, Teun (2005): Discurso, conocimiento e ideología. Reformulación de viejas cuestiones y propuesta de algunas soluciones nuevas. Cuadernos de información y comunicación. 10:285-318.

Venuti, Lawrence, ed. (1992): Rethinking translation: Discourse, subjectivity, ideology. London: Routledge.

Vuorinen, Erkka (1997): News translation as gatekeeping. In: Mary SNELL-Hornby, Zuzana Jettmarová and Klaus KAINDL, eds. Translation as intercultural communication. Amsterdam/Philadelphia: John Benjamins, 161-172.

Wodak, Ruth, Cilia, Rudolf, Reisigl, Martin, et al. (1999): The discursive construction of national identity. Edinburgh: Edinburgh University Press. 